\title{
Mixing Efficiency Study of Nano and Micro Filled PP Systems
}

\author{
H. Hargitai ${ }^{1}$, D. Török ${ }^{2}$ \\ ${ }^{1}$ Széchenyi István University, Department of Materials Science and Technology \\ Egyetem square 1, H-9026 Győr, Hungary \\ E-mail: hargitai@sze.hu \\ ${ }^{2}$ Budapest University of Technology and Economics, Faculty of Mechanical \\ Engineering, Department of Polymer Engineering, Müegyetem rkp. 3, H-1111 \\ Budapest, Hungary \\ E-mail: torok@pt.bme.hu
}

Abstract: In this paper micron and nano sized fillers were compounded with polypropylene homopolymer. First masterbaches were produced with high filler content than samples were injection molded by different filler loading. The effect of using static mixers with different element number was analyzed on the mechanical properties and filler distribution. Tensile properties of PPtalc, PP-boron nitride and PP-graphene systems were investigated and optical microscopic observations were carried out for mapping the distribution of the fillers in the polymer matrix.

Keywords: polypropylene, boron nitride, talc, graphene, filler distribution, tensile properties, static mixer

\section{Introduction}

Since the middle of the last decade, polymeric composites have turned out to be commonly used engineering materials and manufactured in large quantities in order to be used in countless applications in sectors such as automotive, electronics, construction, household goods and etc. [1]. Main advantages of these kinds of materials are their low density and the wide range of mechanical properties, in case of some engineering type the high relative strength and stiffness. The main disadvantages for some application are their limited mechanical properties, low thermal and electrical conductivity. To improve their mechanical, thermal or electrical properties, polymers are often reinforced by incorporating fillers into the matrix.

Electronic industrial applications have special requirements because of the heat generated by the products, which need to be dissipating. Because of the remarkable development in electronics polymer composites having good thermal conduction are in the focus of several researches [2][7]. 
There are several factors which have a great influence on the composite's properties. It is well known that the geometry of the reinforcing particle is an important factor in achieving the appropriate (or optimal) properties of composites. In general, there is an inverse relation between the effectiveness of the reinforcement and the size of the filler (or reinforcing fiber). The greater surface-to-volume ratio of the filler the greater effectiveness can be achieved [4]. With boron nitride $(\mathrm{BN})$ nanopowder, having particle size about $130 \mathrm{~nm}$ polypropylene (PP)/BN composite had two times higher thermal conductivity than that of composite's filled with micron-sized powder [8]. An opposite relation was found by Cheewawuttipong et al. They achieved larger thermal conductivity of $\mathrm{PP} / \mathrm{BN}$ composite using $\mathrm{BN}$ with large $(7-10 \mu \mathrm{m})$ size than that using $\mathrm{BN}$ with small size $(1-2 \mu \mathrm{m})$. They concluded that the network structure of BN would be typically easy to be created by using $\mathrm{BN}$ with large size [3]. Moreover the volume fraction has also strong effect on the properties. Especially in case of conductivity there is a lower limit of applying fillers to form a conductive path on the composite system and by application of smaller particles, especially nano-size fillers better interaction can be achieved and thus higher conductivity [4] [9].

For improving the thermal conductivity of a polymeric material, polymer matrices are usually filled with the thermally conductive fillers like metal powders (aluminum, copper), ceramic powders (alumina diamond, silicon carbide, boron nitride) and carbonbased materials (graphite, carbon fiber) [10]. Zhou et al. found that the combined use of $\mathrm{BN}$ particles and alumina short fiber has synergetic effect and resulted in higher thermal conductivity of composites compared to the BN used alone [5].

To enhance both the conductivity and mechanical properties nanofillers are seems to be very effective. Nanometer sized boron nitride, copper; carbon nanotube and synthetic diamond were compared as conductive fillers by Nurul et al. The greater thermal conductivity was achieved by using carbon nanotubes however the entanglements of the filler resulted in reduced tensile properties [4].

Another attractive nanomaterial is graphene, which is a 2D structured material, planar monolayer of carbon atoms owning exceptional charge transport, thermal, optical, and mechanical properties and thus being studied in nearly every field of science and engineering [11]. There are several paper dealing with the graphene and its derivates, such as graphene oxide (GO) or reduced graphene oxide (RGO) application in polymer composites [12][18]. Song et al. found that $2 \mathrm{vol} \%$ graphene can be is significantly improve the thermal oxidative stability of PP by the due to the barrier effect of its lamellar structure although considerable enhancement of the mechanical properties of PP was achieved by using very low $(0.5 \mathrm{vol} \%)$ amount of graphene [18].

One of the most critical aspects of reinforcing is the adhesion on the fiber-matrix interface. Many papers are dealing with the chemical treatment of the reinforcing fiber or chemical compatibilization during the processing to enhance the interaction between the components [13][15]. By the treatment of graphite using strong mineral acids and oxidizing agents graphite oxide can be produced which is an effective reinforcement. Chemically reduced graphene oxide has a pronounced reinforcing effect in poly(vinyl alcohol), the tensile strength increased three times by adding 3 vol\% graphene while elongation at break showed opposing trends with increasing volume fraction [13]. 
Talc is attractive as a filler for polypropylene (PP) for several reasons, cost effective, acts as nucleating agent in the crystallization process and offers relatively high strength and stiffness [19][21]. However, dispersion and distribution of talc within the polymer have a significant effect on the performance of the composites [19]. There are several way (mechanical or chemical) to reduce agglomeration and improve particle dispersion and distribution [19]. Castillo et al. improved the mechanical properties such as yield strength, elongation at break and toughness of PP/talc composites by grafting acetoxy groups onto the talc surface, although the effect on the modulus is less pronounced [19]. Tang et al investigated graphene oxide-epoxy composites and they found that the highly dispersed RGO resulted in higher strength and fracture toughness of epoxy resin than the poorly dispersed RGO, although no significant differences in both the tensile and flexural moduli was observed regardless of the dispersion level [16].

As it was mentioned above one of the influencing factors to make polymer composites with appropriate mechanical and other physical properties is the distribution of the fillers in the polymer matrix. There are not only chemical methods to achieve good distribution. Using injection molding static mixing nozzles a homogeneous mixing of polymer melt can be created during injection. The resulting high viscous plastics melt flow is homogeneous with regard to colorant, additives and temperature (Fig. 1.). This kind of melt flow mixing of molten polymer prior to injection results in several benefits mainly used in coloring, such as narrower part tolerance, less part distortion, shorter cycle time or improved melt flow [22].
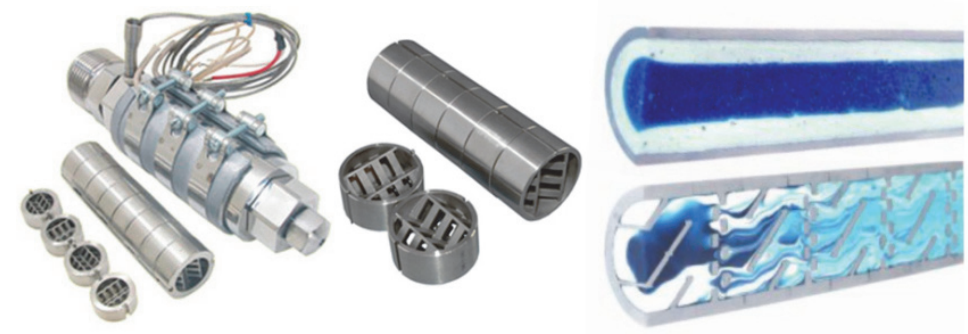

Figure 1. Stamixco injection molding static mixing nozzle with the elements (left);Empty nozzle provides no mixing (right top) and eight SMN mixing elements create homogeneous mixing in a short length (right bottom) [22].

In this study micron and nano sized fillers which are used for producing thermally conductive polymer composites were compounded with polypropylene homopolymer. First masterbaches were made with high filler content than samples were injection molded by different filler loading. The effect of using static mixers was analyzed on the mechanical properties and filler distribution.

\section{Experimental}

\subsection{Materials}

All the materials used in this study are commercially available. Homopolymer polypropylene (PP, TIPPLEN H145 F (TVK, Hungary) was used as matrix material. This 
grade of PP has a specific gravity of $0.9 \mathrm{~g} / \mathrm{cm}^{3}$, a melt flow index of $25 \mathrm{~g} / 10 \mathrm{~min}$ (at $230^{\circ} \mathrm{C}$ and $2.16 \mathrm{~kg}$ of load).

Three kind of fillers were used; micron sized talc (QualChem; $35 \mu \mathrm{m}$, specific gravity of $2.7 \mathrm{~g} / \mathrm{cm}^{3}$ ) and boron nitride (BN) (Henze Hebofil ${ }^{\circledR} 482$; specific gravity of $2.1 \mathrm{~g} / \mathrm{cm}^{3}$ ) and nano sized graphite powder Timrex C-Therm 011 (Timcal Ltd., Switzerland).

\subsection{Sample preparation}

Sample preparation was a two-step process, first melt mixing to make masterbaches than injection molding of test parts.

Polypropylene and the fillers were compounded in a LabTech Scientific-type laboratory twin-screw extruder (screw diameter of $20 \mathrm{~mm}$ and $\mathrm{L} / \mathrm{D}$ ratio of 44 ). The zone temperatures of the extrusion were 190 to $240^{\circ} \mathrm{C}$ After extrusion, the composite was solidified and cooled in a water bath then pelletized. In the melt mixing step talc-PP, BNPP and graphene-PP masterbaches were produced; $30 \mathrm{vol} \%$ of talc, same amount of boron nitride or $2 \mathrm{vol} \%$ of graphene were incorporated separately into the PP melt, producing tree different masterbaches.

Arburg 370S 700-290 Advance injection molding machine with screw diameter of 30 $\mathrm{mm}$ has been used for sample preparation by varying the amount of the fillers and mixing conditions. The filler content of the composite samples can be seen in Table 1.

Table 1. Composition of the filled PP materials

\begin{tabular}{|l|c|c|c|c|c|}
\hline \multirow{2}{*}{$\begin{array}{c}\text { Filler content } \\
\text { [volume\%] }\end{array}$} & \multirow{2}{*}{$\begin{array}{c}\text { Masterbach } \\
\text { compounds }\end{array}$} & \multicolumn{3}{|c|}{ Injection molded specimen } \\
\cline { 3 - 6 } & No.1 & No.2 & No.3 & No.4 \\
\hline Talc & 30 & - & 5 & 10 & 20 \\
\hline Boron nitride & 30 & - & 5 & 10 & 20 \\
\hline Graphene & 2 & 0.2 & 0.5 & 1 & 2 \\
\hline
\end{tabular}

From the masterbaches plaque specimens having $80 \times 80 \times 2 \mathrm{~mm}$ in dimension were injection molded. In the mold a fan gate measuring $1 \mathrm{~mm}$ in thickness were used. The injection molding parameters are summarized in Table 2.

Table 2. Injection molding set-up parameters

\begin{tabular}{|l|c|}
\hline Injection molding parameter & Value \\
\hline Injection volume $\left[\mathrm{cm}^{3}\right]$ & 49 \\
\hline Injection rate $\left[\mathrm{cm}^{3} / \mathrm{s}\right]$ & 50 \\
\hline Holding pressure $[\mathrm{bar}]$ & $80 \%$ of the injection pressure \\
\hline Holding time $[\mathrm{s}]$ & 10 \\
\hline Residual Cooling time $[\mathrm{s}]$ & 10 \\
\hline Clamping force $[\mathrm{kN}]$ & 650 \\
\hline Screw rotational speed $[\mathrm{m} / \mathrm{min}]$ & 15 \\
\hline Melt temperature $\left[{ }^{\circ} \mathrm{C}\right]$ & 200 \\
\hline Temperature of the mold $\left[{ }^{\circ} \mathrm{C}\right]$ & 50 \\
\hline
\end{tabular}


To study the effect of static mixers on the filler distribution Stamixco SMN type static mixers with 5 and 8 elements has been used in the injection molding process. Reference samples were also made without using static mixer.

\subsection{Test methods}

\section{Tensile test}

Three pieces of small size dump-bell shaped 5A type specimens according to the MSZ EN ISO 527-1:1999 standard were cut from the injection molded plates by waterjet equipment parallel with the injection molding direction (Fig. 2). Tensile tests were carried out at room temperature on a standard tensile Zwick machine; model Z020 by using crosshead speed of $2 \mathrm{~mm} / \mathrm{min}$ and clamping length of $50 \mathrm{~mm}$.

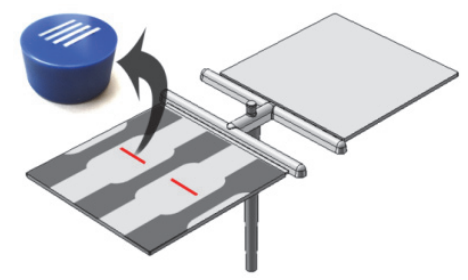

Figure 2. Preparation of dumbbell specimens from the injection molded plaque plates and the positions (red lines) of the cross-sections for optical microscopy

Stress-strain curves were obtained for each specimen, where Young's modulus and tensile strength were determined. Tests were carried out on at least five samples for each composite in order to minimize the error.

\section{Optical microscopic investigations}

To study the distribution of the fillers in the PP matrix the cross section in the same position of each sample were analyzed. The polished samples were observed by Zeiss Axio Imager M1 optical microscope with different magnifications (50X, 200X, 500X and 1000X) and imaging modes such as Polarized, Bright Field, Dark Field. Differential Interference Contrast (DIC) technique relies on Polarized illumination was also used to create a 3D effect of the specimen's surface. The prisms placed in the condenser and in the back focal plane of the objective modify the normal extinction resulting from the crossed polarizers.

\section{Results and discussion}

\subsection{Tensile properties}

The tensile strength and modulus of talc and boron nitride filled composites are shown in Figure 3. It was observed that the tensile strengths decreased, while the modulus increased with the filler content for both talc and boron nitride. Decrease of the strength could be due to the week interfacial bond between the components. 

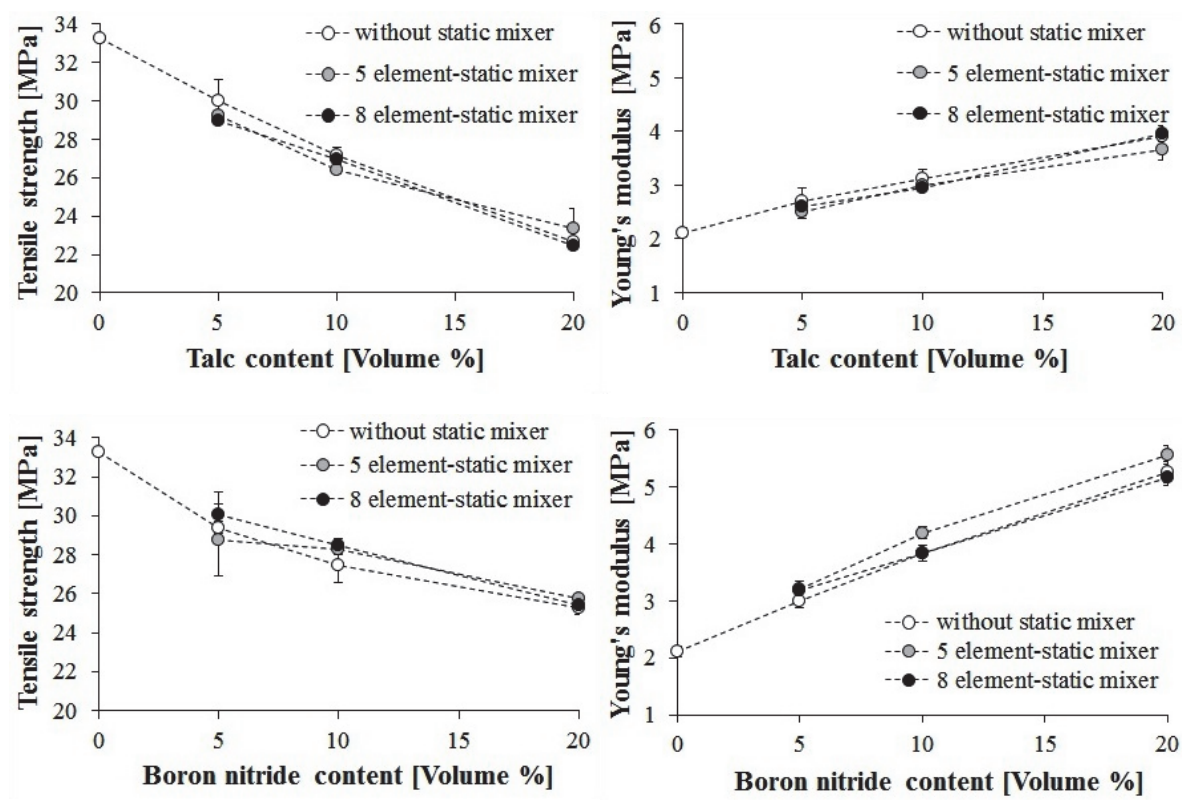

Figure 3. Tensile strength and Young's modulus of talc (top) and boron nitride (bottom) filled polypropylene composites as a function of filler content made without, with 5 and 8 element static mixers

Lower decrease of the strength and higher increase of the modulus of boron nitride - $\mathrm{PP}$ composites compared to the talc composites was found. By analyzing the effect of the static mixer no significant differences can be observed between the mechanical parameters by using the 5 or 8 element systems. In case of higher filler content a slight increase of properties can be seen in comparison with the composites made without static mixer.

Figure 4. shows the results of the nano-filled graphene-PP composites. The same tendencies with slighter effect are occurred as in case of the talc and BN composites.
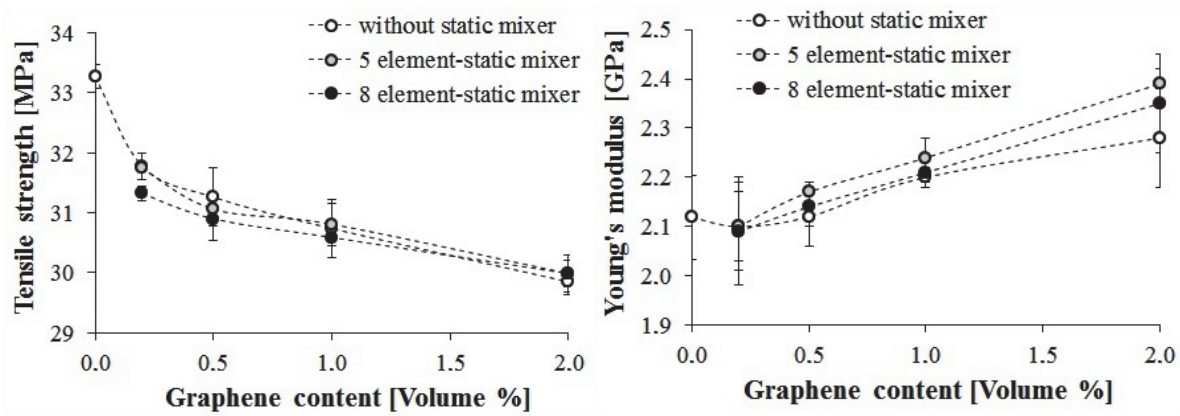

Figure 4. Tensile strength and Young's modulus of graphene-polypropylene composites as a function of filler content made without, with 5 and 8 element static mixers 
For comparison the effect of the three types of fillers each result are summarized in the diagrams of Figure 5. From the point of view the tensile properties the best results were obtained by applying boron nitride fillers. The same tendencies are clearly seen as the slight effect of the static mixing on the tensile properties of the composites.
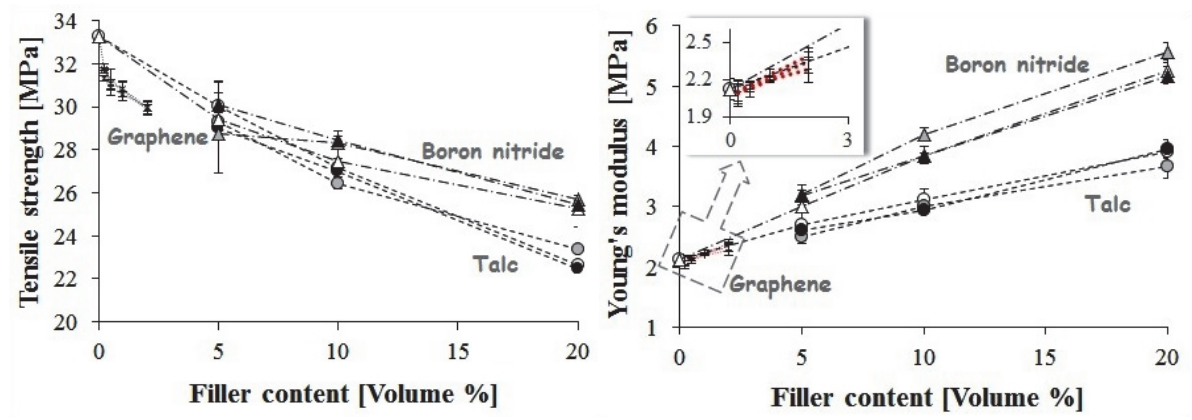

Figure 5. Tensile strength and Young's modulus of the composites for each filler type as a function of filler content made without, with 5 and 8 element static mixers

\subsection{Microscopic analysis}

For analysis the distribution of the filler particles in the polypropylene optical microscopic pictures were taken from the polished cross-sectional surfaces of the composites. Bright Field imaging mode or DIC prism in polarized mode was applied to get pictures which can be analyzed.

By evaluating the microscopic images no significant differences were found between the composites made by different mixing modes. No evaluable pictures were taken from the graphene-PP composites. On Figure 6. the slight effect of using 8 element static mixer can be seen in case of boron nitride filled composites for each filler content. 

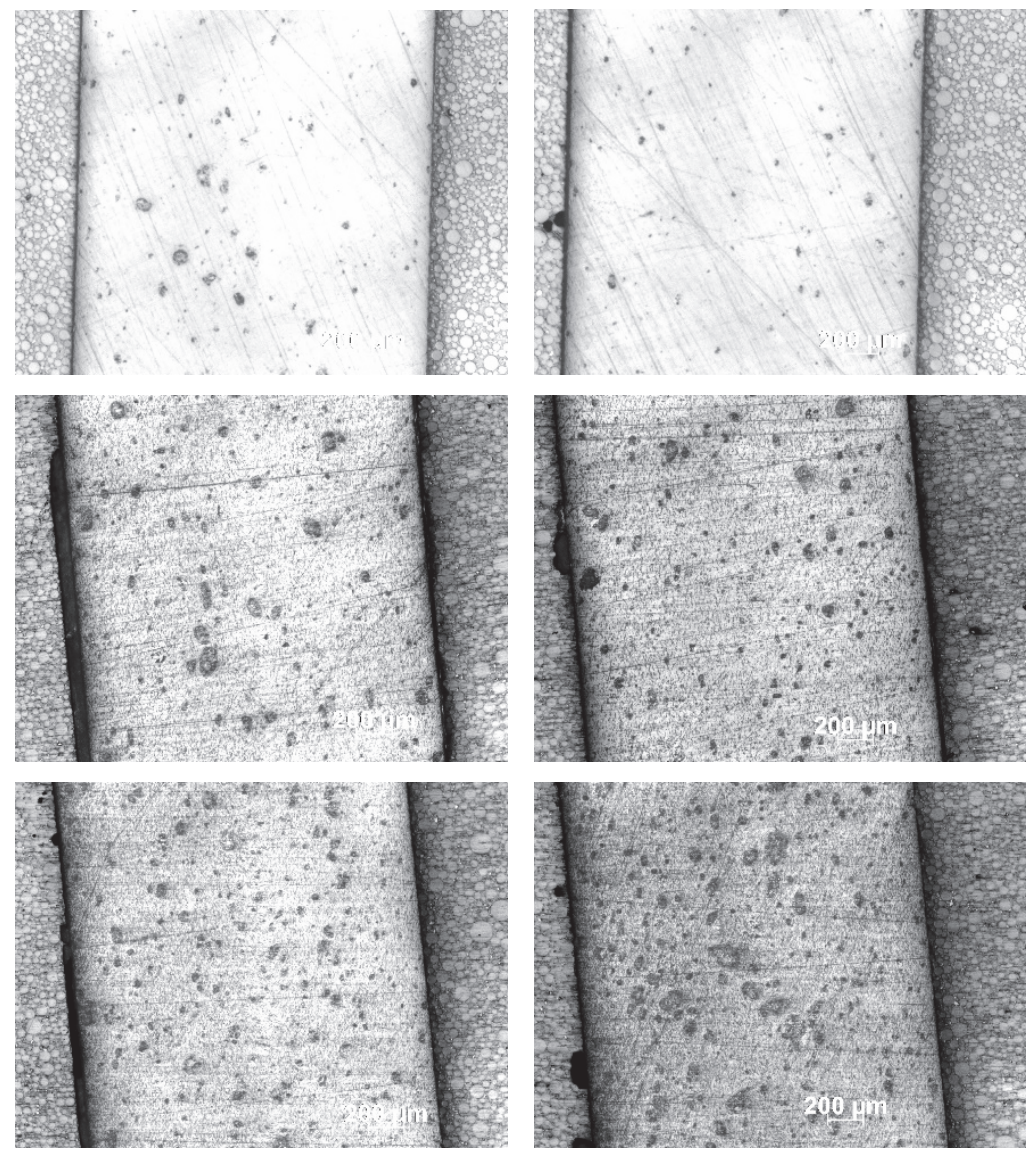

Figure 6. Optical microscopic images (Bright Field, 50X) of boron nitride-PP composites produced without (left) and with 8 elements static mixer (right) with 5 vol\% (top). $10 \mathrm{vol \%}$ (middle) and $20 \mathrm{vol} \%$ (bottom) filler content

Differential Interference Contrast (DIC) prism was used on polarized illumination to create 3D-like pictures. Smaller agglomeration sizes can be found by using 8 element static mixer in case of both $5 \mathrm{vol} \%$ boron nitride and $5 \mathrm{vol} \%$ talc filled composites (Figure 7.). 

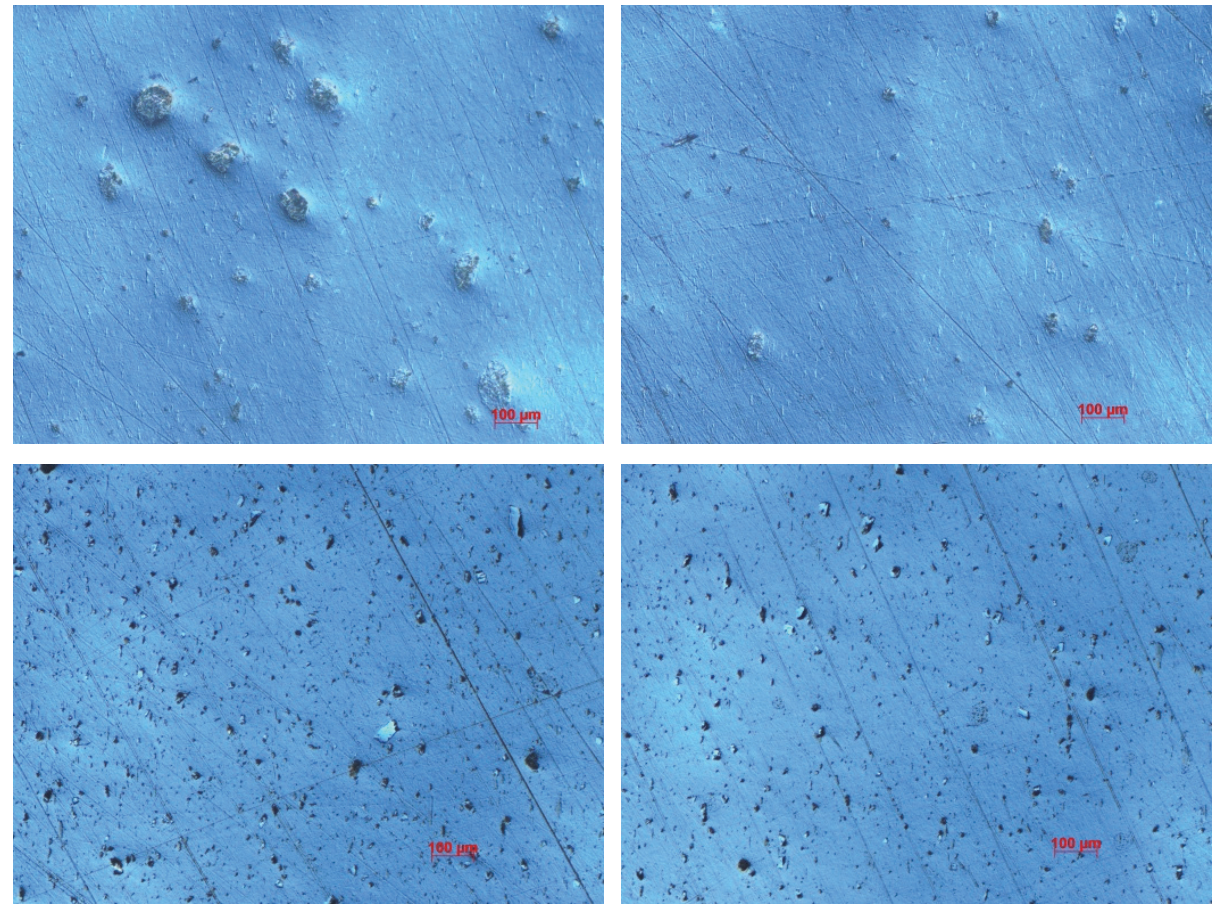

Figure 6. Optical microscopic images (polarised light and DIC prism, 100X) of 5 vol\% boron nitride-PP (top) and 5 vol\% talc-PP (bottom) composites produced without (left) and with 8 elements static mixer (right)

\section{Conclusions}

In our experiments we focused on thermal conductive polymeric composite materials, especially to affect the distribution of the fillers in the polymeric matrix material. Micron sized boron nitride and talc fillers and nanosized graphene were compounded with polypropylene homopolymer. Masterbaches were made with high filler content in laboratory twin screw extruder than samples were injection molded by different filler loading. Static mixers with 5 and 8 elements were used and their effect on the tensile properties and the filler distribution were analyzed.

Based on the tensile test results of PP-talc, PP-boron nitride and PP-graphene systems and the optical microscopic observations of the polished cross-sectional surfaces of the composites the following can be concluded:

- Tensile strength of each composite decreased with the filler content, while an opposite tendency was observed in case of Young's modulus.

- No significant effect of the static mixers was found, but increasing the filler content the use of static mixers showed a slight increase in the properties compared to those, which have made without static mixer. 
- In comparison the three different filler composites, the best properties were achieved by incorporating boron nitride into the matrix PP.

- The optical microscopic images show no significant effect of the static mixing.

Based on our experimental results and the review of the scientific literature the positive effect of the fillers is depending on several factors, such as filler dispersion and distribution, filler content and filler size. Beside these factors the strength of the interfacial adhesion may has the greatest impact on the mechanical properties. The week interaction between the components resulted in the decreasing strength of the composites compared to the neat polymer. In further researches the interfacial adhesion should be investigated as well.

\section{Acknowledgement}

This paper was supported by the János Bolyai Research Scholarship of the Hungarian Academy of Sciences.

The research work presented in this paper was carried out as part of the TÁMOP4.2.2.A-11/1/KONV-2012-0029 project in the framework of the New Széchenyi Plan. The realization of this project is supported by the European Union, and co-financed by the European Social Fund.

\section{References}

[1] Hargitai, H., Rácz, I.: Applications of Macro- and Microfiller-Reinforced Polymer Composites in Polymer Composites, vol. 1, Macro- and Microcomposites, Editors: Sabu, T., Kuruvilla, J., Malhotra, S. K., Goda, K., Sreekala, M. S., Wiley-VCH Verlag, Weinheim, pp. 749-791, 2012

DOI: 10.1002/9783527645213.ch23

[2] Suplicz, A., Szabo, F., Kovacs, J. G.: Injection molding of ceramic filled polypropylene: The effect of thermal conductivity and cooling rate on crystallinity, Thermochimica Acta, vol. 574, pp. 145-150, 2013

DOI: $10.1016 /$ j.tca.2013.10.005

[3] Cheewawuttipong, W., Fuoka, D., Tanoue, S., Uematsu, H., Iemoto, Y.: Thermal and Mechanical Properties of Polypropylene/Boron Nitride Composites, Energy Procedia, vol. 34, pp. 808-817, 2013 DOI:10.1016/j.egypro.2013.06.817

[4] Nurul, M. S., Mariatti, M.: Effect of thermal conductive fillers on the properties of polypropylene composites, Journal of Thermoplastic Composite Materials, vol. 26, no. 5, pp. $627-639,2013$

DOI: $10.1177 / 0892705711427345$

[5] Zhou, W., Qi, S., An, Q., Zhao, H., Liu, N.: Thermal conductivity of boron nitride reinforced polyethylene composites, Materials Research Bulletin, vol. 42, no. 10, pp. 1863-1873, 2007

DOI: 10.1016/j.materresbull.2006.11.047

[6] Suplicz, A., Kovács, J. G.: Development of Thermally Conductive Polymer Materials and their Investigation, Materials Science Forum, vol. 729, pp. 80-84, 2013 
DOI: $10.4028 /$ www.scientific.net/MSF.729.80

[7] Suplicz, A., Kovács, J. G.: Thermally Conductive Polymer Compounds for Injection Moulding: Synergetic Effect of Hexagonal Boron Nitride and Talc, Journal of Reinforced Plastics And Composites, vol. 32, no. 16, pp. 1234-1240, 2013

DOI: $10.1177 / 0731684413489755$

[8] Muratov, D.S., Kuznetsov, D.V., Il'inykh, I.A., Mazov, I.N., Stepashkin, A.A., Tcherdyntsev, V.V.: Thermal conductivity of polypropylene filled with inorganic particles, Journal of Alloys and Compounds, vol. 586, suppl. 1, pp. S451-S454, 2014

DOI: $10.1016 /$ j.jallcom.2012.11.142

[9] Schöne, J., Kotter, I., Grellmann, W.: Properties of Polypropylen Talc Compounds with Different Talc Particle Size, Journal of Plastics Technology, vol. 8, no. 2, pp. 231-251, 2012

[10] Hong, J., Park, D. W., Shim, S. E.: A review on thermal conductivity of polymer composites using carbon-based fillers : carbon nanotubes and carbon fibers, Carbon Letters, vol. 11., no. 4., pp. 347-356, 2010

DOI : $10.5714 /$ CL.2010.11.4.347

[11] Singh, V., Joung, D., Zhai, L., Das, S., Khondaker, S. I., Seal, S.: Graphene based materials: Past, present and future, Progress in Materials Science, vol. 56, no. 8, pp. 1178-1271, 2011

DOI: 10.1016/j.pmatsci.2011.03.003

[12] Kuilla, T., Bhadra, S., Yao, D., Kim, N. H., Bose, S., Lee, J. H.: Recent advances in graphene based polymer composites, Progress in Polymer Science, vol. 35, no. 11, pp. 1350-1375, 2010 DOI: 10.1016/j.progpolymsci.2010.07.005

[13] Potts, J. R., Dreyer, D. R., Bielawski, C. W., Ruoff, R. S.: Graphene-based polymer nanocomposites, Polymer, vol. 52, no. 1, pp. 5-25, 2011

DOI: 10.1016/j.polymer.2010.11.042

[14] Hu, K., Kulkarni, D. D., Choi, I., Tsukruk, V. V.: Graphene-polymer nanocomposites for structural and functional applications, Progress in Polymer Science, 2014 DOI: 10.1016/j.progpolymsci.2014.03.001

[15] Yang, X., Wang, X., Yang, J., Li, J., Wan, L.: Functionalization of graphene using trimethoxysilanes and its reinforcement on polypropylene nanocomposites, Chemical Physics Letters, vol. 570, pp. 125-131, 2013

DOI: 10.1016/j.cplett.2013.03.069

[16] Tang, L-C., Wan, Y.-J., Yan, D., Pei, Y-B., Zhao, L., Li, Y-B., Wu, L-B., Jiang, J$\mathrm{X} ., \mathrm{Lai}, \mathrm{G}-\mathrm{Q} .:$ The effect of graphene dispersion on the mechanical properties of graphene/epoxy composites, Carbon, vol. 60, pp. 16-27, 2013

DOI: 10.1016/j.carbon.2013.03.050

[17] Milani, M. A., González, D., Quijada, R., Basso, N. R.S., Cerrada, M. L., Azambuja, D. S., Galland, G. B.: Polypropylene/graphene nanosheet nanocomposites by in situ polymerization: Synthesis, characterization and fundamental properties, Composites Science and Technology, vol. 84, pp. 1-7, 2013

DOI: 10.1016/j.compscitech.2013.05.001 
[18] Song, P., Cao, Z., Cai, Y., Zhao, L., Fang, Z., Fu, S.: Fabrication of exfoliated graphene-based polypropylene nanocomposites with enhanced mechanical and thermal properties, Polymer, vol. 52, no. 18, pp. 4001-4010, 2011

DOI: 10.1016/j.polymer.2011.06.045

[19] Castillo, L., Barbosa, S., Capiati, N.: Improved performance of polypropylene/talc composites, Society of Plastics Engineers Plastics Research Online, 2012 DOI: $10.2417 /$ spepro.004405

[20] Rao Patnaik, K.S.K., Sirisha Devi, K., Kiran Kumar, V.: Non-isothermal Crystallization Kinetics of Polypropylene (PP) and Polypropylene (PP)/Talc

Nanocomposite, International Journal of Chemical Engineering and Applications vol. 1 , no. 4, pp. 346-353, 2010

DOI: $10.7763 /$ IJCEA.2010.V1.60

[21] Castillo, L. A., Barbosa, S. E., Capiati, N. J.: Influence of talc morphology on the mechanical properties of talc filled polypropylene, Journal of Polymer Research, vol. 20, pp. 152-160, 2013

DOI 10.1007/s10965-013-0152-2

[22] Schneider, G., Ungvári, Gy.: Stamixco static mixer for producing homogeious melt during injection molding (in Hungarian), Müanyag és Gumi, vol. 44. no. 3, pp. 111-115, 2007

[23] Zsíros, L., Kovács, J. G.: Optimization of homogenizing capacity of injection moulding machines (in Hungarian), Müanyag és Gumi, vol. 50. no. 9, pp. 347350,2013 